\title{
What We Can Learn from the Nordic Model
}

Considered role models for governance, equality, and social and economic policy, the Nordic countries rank near the top of every quality of living standard survey worldwide. The state welfare system, access to quality education and wage equality characterise the Nordic model and contribute to the countries' continued growth and prosperity. But they also face challenges due to ageing populations, increasing inequality and digitalisation. What are the lessons to be learned from the Nordic countries? How can the Nordic model help shape future economic policy in Europe? How will the Nordic countries confront the challenges to their system? This Forum examines various angles and provides relevant applications for the future.

The Nordic Model of Economic Development and Welfare: Recent Developments and Future Prospects

Roberto lacono, The Norwegian University of Science and Technology, Trondheim, Norway.

The Nordic Model and Structural Change: Lessons from the Collapse of Saab Automobile AB

Mark T. Nance, North Carolina State University, Raleigh, NC, USA.

Jack Daly, Duke University, Durham, NC, USA.

Social Corporatism and Capital Accumulation: The Fate of the Nordic Model Jonathan Perraton, University of Sheffield, UK.

Elitism in Higher Education and Inequality: Why Are the Nordic Countries So Special?

Elise S. Brezis, Bar-llan University, Ramat Gan, Israel.

The Success of the Nordic Countries as a Blueprint for Small Open Economies Johannes Tiemer, University of Duisburg-Essen, Germany. 